\title{
陕西省植被覆盖时空变化及其对极端气候的响应
}

\author{
高 港，孙 虎*，徐峑尧，张世芳
}

陕西师范大学地理科学与旅游学院, 西安 710119

摘要:基于 2001-2018 年 MODIS NDVI 数据,从生态分区视角分析陕西省归一化植被指数( NDVI) 的时空变化特征,并结合该 地区 31 个气象站点日值数据, 探讨 NDVI 对极端气温和极端降水指数的响应特征。结果表明: (1) 陕西省及其各生态区的 NDVI 变化均显著上升, 整体呈南高北低的分布特点, 其中秦巴山地落叶与阔叶林生态区 (IV) NDVI 值最高为 0.86 , 陕北北部典 型草原生态区 $(I)$ NDVI 值最低为 0.38 。(2) 年际尺度上,陕西省 NDVI 与极端气温暖极值 (暖夜日数) 和极端降水指数总体呈 显著正相关 $(P<0.05)$, 在陕西省北部 NDVI 变化主要受极端降水的影响, 南部则对极端气温的敏感度更高。(3)多年月尺度 上, 各生态区 NDVI 对极端气温冷极值(最低气温、日最低气温的极低值和日最高气温的极低值) 和极端气温暖极值(最高气温、 日最低气温的极高值和日最高气温的极高值) 存在明显的滞后性, 滞后时间多为 3 个月; 与极端降水指数 (单日最大降水量和 连续 5 日最大降水量) 的滞后时间为 2 个月,说明陕西省内 NDVI 对极端气候的响应具有显著的滞后效应。

关键词: 归一化植被指数 (NDVI); 时空特征; 极端气候; 滞后效应; 陕西省

\section{Temporal and spatial variation of vegetation cover and its response to extreme climate in Shaanxi Province}

GAO Ying, SUN Hu* ${ }^{*}$ XU Yinyao, ZHANG Shifang

College of Geography and Tourism, Shaanxi Normal University, Xi'an 710119, China

\begin{abstract}
Vegetation plays an important role in the terrestrial ecosystem. Under the background of global warming, the response of vegetation cover to climate change has become an important research field. Normalized Difference Vegetation Index (NDVI) is commonly used to study the response of vegetation change to temperature and precipitation on a regional scale. In recent years, the frequent occurrence of extreme climate events has increased the risk and vulnerability of terrestrial ecosystems and endangered ecological security. Shaanxi province is located in the hinterland of China, with a large north-south span and obvious regional differences in hydrothermal conditions and surface ecological environment. Therefore, it is necessary to study the dynamic change of NDVI and its response to extreme climate, which can provide theoretical evidence of ecosystem evolution and ecological environment conservation in Shaanxi Province. Based on MODIS NDVI data from 2001 to 2018, the spatio-temporal variation pattern of NDVI was analyzed from the perspective of different ecological areas in Shaanxi Province. The response characteristics of NDVI to extreme temperature and precipitation indices were also discussed by using the daily meteorological observations from 31 stations in this region. The results showed that (1) the variation of NDVI increased significantly and the spatial difference of NDVI value was obvious in Shaanxi Province and its ecological areas. The high value of NDVI distributed in the south, whereas the low value of NDVI distributed in the north. The decreasing order of the value of NDVI of the different ecological areas was as follows: ecological region of
\end{abstract}

基金项目: 陕西省水利厅基金项目(201510085)

收稿日期: 2021-01-09; 网络出版日期:2021-10-11

*通讯作者 Corresponding author.E-mail: kycjh6@ snnu.edu.cn 
deciduous and broad-leaved forest in Qinba Mountain ( IV) > agricultural ecological area of Fenwei Basin ( III) > agricultural and grassland ecological region of the Loess Plateau (II) > typical grassland ecological area in northern Shaanxi (I). Meanwhile, the lowest value of NDVI was 0.38 and the highest value was 0.86 . (2) The correlation between NDVI and extreme climate indices showed that annual NDVI in each ecological area was significantly positively correlated with TN90p and extreme precipitation indices. However, extreme precipitation had an important impact on vegetation growth in the north of Shaanxi Province, and extreme temperature was the main factor in the south. (3) On the monthly scale, the NDVI had a significant lag time of 3 months with extreme temperature indices, including $\mathrm{TMIN}_{\text {mean }}, \mathrm{TN}_{\mathrm{n}}, \mathrm{TX}_{\mathrm{n}}, \mathrm{TMAX}_{\text {mean }}$, $\mathrm{TN}_{\mathrm{x}}$, and $\mathrm{TX}_{\mathrm{x}}$, while had a lag time of 2 months with extreme precipitation indexes in each ecological area. In general, the results effectively revealed the response of vegetation to climate fluctuations in Shaanxi Province.

Key Words: NDVI; temporal and spatial variation; extreme climate; lag effect; Shaanxi Province

植被作为陆地生态系统的主体, 是各个圈层进行物质能量交换和信息传递的关键 ${ }^{[1]}$, 在气候调节、水土 保持以及生物多样性保护等生态服务功能中发挥着重要作用 ${ }^{[2]}$ 。植被指数是宏观表征地表植被覆盖变化的 有力度量, 目前常用植被指数包括: 归一化植被指数 (Normalized Difference Vegetation Index, NDVI), 增强型植 被指数 (Enhanced Vegetation Index, EVI) 和叶面积指数 (Leaf Area Index, LAI) 等 ${ }^{[3-5]}$ 。其中, NDVI 不仅能明 显指示地表植被生长状况和生态环境的演变, 而且与植被覆盖度存在显著的线性相关关系 ${ }^{[6]}$, 能够较好地反 映区域内植被覆盖情况, 因此, NDVI 常用于反映区域内植被覆盖变化对生态因子(如气候、土地利用、人类活 动等) 的响应 ${ }^{[7-8]}$ 。

在全球气候变暖的背景下, 研究气候变化与陆地生态系统之间的关系是国际社会较为关注的问题, 其中 监测植被动态并量化植被生长对气候的响应成为全球变化研究的重要领域 ${ }^{[9-10]}$ 。目前, 国外学者分别在全 球尺度 ${ }^{[1]}$ 、全国尺度 ${ }^{[12]}$ 和区域尺度 ${ }^{[13]}$ 研究了不同植被类型 NDVI 变化特征与气候因素的相关关系,结果表 明植被生长对气温和降水非常敏感; 国内学者也通过应用 NDVI 数据分析表明气候变化对植被生长具有明显

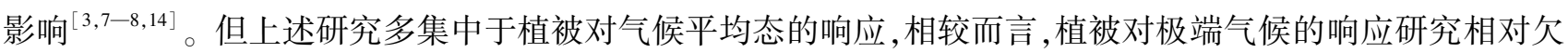
缺 ${ }^{[15]}$ 。极端气候事件由于其突发性强且强度较大 ${ }^{[16]}$, 影响着陆地生态系统的植被动态变化, 并具有一定的 区域差异性 ${ }^{[17]}$, 因此有必要开展植被对极端气候的响应研究。由于气候变化对植被影响具有累积效应, 所以 植被的反馈通常会出现时滞 ${ }^{[18]}$ 。Arnone 等通过对照实验表明,草地生态系统中的极端气候事件会导致当前 和随后几年的净生态系统生产力下降, 时滞为两年 ${ }^{[19]}$ 。同时, 在我国沿海 ${ }^{[20]}$ 、黄土高原 ${ }^{[21]}$ 、内蒙古 ${ }^{[22]}$ 等生态 敏感区研究发现,植被对极端气候的响应也具有一定的时滞性,说明当气候变化超过植被的承受能力时,在一 段时间后植被生长才趋于对气候做出反应 ${ }^{[23-24]}$ 。所以,在探索植被对极端气候的响应研究中应该考虑滞后 效应,对于更好地了解地表生态环境对气候变化的脆弱性具有重要意义。

在大区域的研究中,地表生态环境的差异会使植被对气候变化的响应程度不同 ${ }^{[25]}$, 所以从更细致的角度 分析大区域内各类型生态系统的植被时空变化及气候变化特征尤为重要。生态分区是按照地形地貌、水热组 合、植被特征等自然条件,将大区域划分或合并形成不同等级的区域系统 ${ }^{[26]}$, 所以从生态分区视角分析能够 更好地揭示极端气候对植被的影响。陕西省地处西部内陆, 南北纬度跨度大, 水热条件与地表生境异质性显 著, 又是中国水土流失、沙化等环境问题比较严重的地区之一, 所以众多学者在陕西省开展了植被对气候变化 的响应研究 ${ }^{[27-28]}$, 而关于极端气候对植被的影响尚不明确。因此, 本文基于生态分区, 利用 2001-2018 年 MODIS NDVI 数据, 结合同期日气温和降水数据, 分析陕西省植被覆盖的年际变化趋势及其对极端气候的时 空响应, 并在多年月尺度上探讨陕西省植被覆盖对极端气候的滞后效应, 对于认识该地区生态系统演变、进行 生态环境保护具有一定的理论与现实意义。

\section{1 研究区概况}

陕西省 $\left(105^{\circ} 29^{\prime}-111^{\circ} 15^{\prime} \mathrm{E}, 31^{\circ} 42^{\prime}-39^{\circ} 35^{\prime} \mathrm{N}\right)$ 位于中国西部内陆地区, 总面积 20.56 万 $\mathrm{km}^{2}$ 。陕西省海 
拔在 500-2000 m, 地表高程差异较大, 呈南北高中部 低的地势格局; 省内地貌类型复杂多样, 兼具高原、山 地、平原和盆地等地形。年降水量 $576.9 \mathrm{~mm}$, 年均气温 $13.0^{\circ} \mathrm{C}$, 无霜期 $218 \mathrm{~d}$ 左右 ${ }^{[29]}$, 陕西省纵跨 3 个气候带, 自北向南依次为中温带、暖温带、北亚热带,南北气候类 型多样且差异显著, 即长城沿线以北为温带干旱半干旱 气候、陕北黄土丘陵沟壑区和关中平原为暖温带半干旱 和半湿润气候、陕南盆地则为北亚热带湿润气候、山地 大部分为暖温带湿润气候 ${ }^{[30]}$ 。

根据中国生态区划分标准 (http://www. ecosystem. $\operatorname{csdb} . c n /)$, 同时结合省内自然条件,陕西省可分为四个 生态区 (图 1), 从北向南依次为: 陕北北部典型草原生 态区 (I)、黄土高原农业与草原生态区 ( II) 、汾渭盆地农 业生态区 ( III) 、秦巴山地落叶与阔叶林生态区 (IV)。 其中, 秦巴山地落叶与阔叶林生态区所占面积最大, 陕 北北部典型草原生态区所占面积最小。

\section{2 材料与方法}

\section{1 数据来源与预处理}

NDVI 数据来源于美国国家航空航天局 (NASA) 数 据中心提供的 2001-2018 年 MODISQ1 数据产品,空间

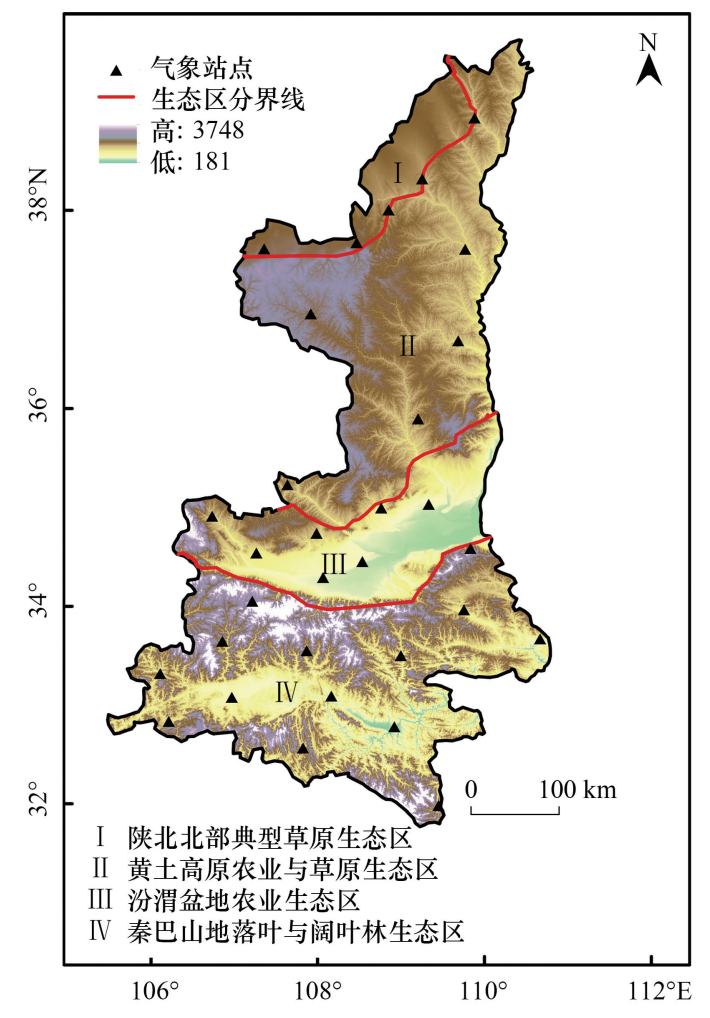

图 1 研究区位置及其气象站点 分辨率为 $250 \mathrm{~m}$,时间分辨率为 $16 \mathrm{~d}$ 。陕西省在全球正 弦投影系统中编号为 h26v05 和 h27v05, 选取全年 1-12 月的影像资料,该产品已进行去云、辐射校正、大气校 正等处理。由于最大值 NDVI 能够更好地表示地表植被覆盖状况, 故采用最大合成法 (MVC) ${ }^{[31]}$ 得到逐月 NDVI 数据,用于分析陕西省植被覆盖时空变化以及与极端气候的相关性。

气象数据来源于国家气象科学数据中心 (https://data.cma.cn), 选取陕西省内时间序列完整一致的 31 个 气象站点 $(2000-2018$ 年), 利用日气温和日降水量数据在 RClimdex 1.0 计算出 15 个极端气候指数,包括 11 个极端气温指数和 4 个极端降水指数, 上述极端气候指数是结合陕西省气候条件, 从 ETCCDI( Expert Team for Climate Change Detection and Indices) 所提供的指标体系中选取, 可以表征气温温差的边缘态, 以及降水的极 端态过程 ${ }^{[32]}$, 能够捕获极端气候, 并能够有效地反映极端气候对植被动态变化的影响 ${ }^{[33]}$, 具体定义见表 1 。

2.2 研究方法

\subsection{1 趋势分析}

Theil-Sen 斜率估计是用于分析长时间序列变化趋势的一种非参数估计方法 ${ }^{[34]}$ 。计算公式如下：

$$
\beta=\operatorname{median}\left(\frac{\mathrm{NDVI}_{j}-\mathrm{NDVI}_{i}}{j-i}\right) \forall j>i
$$

式中, median 表示中位数函数; $i$ 和 $j$ 为时间序列数据, $\mathrm{NDVI}_{i}$ 和 $\mathrm{NDVI}_{j}$ 表示第 $i j$ 年份的 NDVI 值。当 $\beta>0$ 时, 表示 NDVI 呈上升趋势; $\beta<0$ 时,表示 NDVI 呈下降趋势。

\subsubsection{Mann-Kendal 检验}

Mann-Kendall 是一种非参数统计检验方法 ${ }^{[35-36]}$, 由于其不受缺失值和异常值的影响, 在水文、气象时间 序列分析中广泛应用,检验方法如下： 
表 1 极端气温指数与极端降水指数定义

Table 1 Definition of extreme temperature indices and extreme precipitation indices

\begin{tabular}{|c|c|c|c|c|}
\hline 类别 & 代码 & 名称 & 定义 & 单位 \\
\hline Category & ID & Name & Definition & Unit \\
\hline 极端气温冷极值 & TMIN $_{\text {mean }}$ & 最低气温 & 每月内日最低气温平均值 & ${ }^{\circ} \mathrm{C}$ \\
\hline \multirow[t]{4}{*}{ Extreme cold temperature indices } & TN10p & 冷夜日数 & 日最低气温 $<10 \%$ 分位值的日数 & $\mathrm{d}$ \\
\hline & TX10p & 冷昼日数 & 日最高气温 $<10 \%$ 分位值的日数 & d \\
\hline & $\mathrm{TN}_{\mathrm{n}}$ & 日最低气温的极低值 & 每月内日最低气温的最小值 & ${ }^{\circ} \mathrm{C}$ \\
\hline & $\mathrm{TX}_{\mathrm{n}}$ & 日最高气温的极低值 & 每月内日最高气温的最小值 & ${ }^{\circ} \mathrm{C}$ \\
\hline 极端气温暖极值 & TMAX $_{\text {mean }}$ & 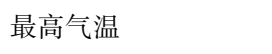 & 每月内日最高气温平均值 & ${ }^{\circ} \mathrm{C}$ \\
\hline \multirow[t]{4}{*}{ Extreme warm temperature indices } & TN90p & 暖夜日数 & 日最低气温>90\%分位值的日数 & $\mathrm{d}$ \\
\hline & TX90p & 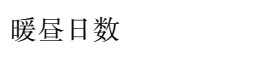 & 日最高气温> $90 \%$ 分位值的日数 & $\mathrm{d}$ \\
\hline & $\mathrm{TN}_{\mathrm{x}}$ & 日最低气温的极高值 & 每月内日最低气温的最大值 & ${ }^{\circ} \mathrm{C}$ \\
\hline & $\mathrm{TX}_{\mathrm{x}}$ & 日最高气温的极高值 & 每月内日最高气温的最大值 & ${ }^{\circ} \mathrm{C}$ \\
\hline 其他 Others & DTR & 气温日较差 ～～～～～～～～ & 年内日最高气温与最低气温的差值 & ${ }^{\circ} \mathrm{C}$ \\
\hline 极端降水指数 & PRCPTOT & 年总降水量 & 年内日降水量 $\geqslant 1 \mathrm{~mm}$ 的降水总量 & $\mathrm{mm}$ \\
\hline \multirow[t]{3}{*}{ Extreme precipitation indices } & Rx1day & 单日最大降水量 & 每月最大 1 日降水量 & $\mathrm{mm}$ \\
\hline & Rx5day & 连续 5 日最大降水量 & 每月连续 5 日最大降水量 & $\mathrm{mm}$ \\
\hline & SDII & 年均雨日降水强度 & $\begin{array}{l}\text { 年内日降水量 } \geqslant 1 \mathrm{~mm} \text { 的总量与总日数 } \\
\text { 的比值 }\end{array}$ & $\mathrm{mm} / \mathrm{d}$ \\
\hline
\end{tabular}

假设序列 $\left\{\mathrm{NDVI}_{i}\right\}$, 其中 $i=1,2, \cdots, i, \cdots j, \cdots, n$ 。定义检验统计量 $S$ :

$$
\begin{gathered}
S=\sum_{i=1}^{n-1} \sum_{j=i+1}^{n} \operatorname{sgn}\left(\mathrm{NDVI}_{j}-\mathrm{NDVI}_{i}\right) \\
\operatorname{sgn}\left(\mathrm{NDVI}_{j}-\mathrm{NDVI}_{i}\right)=\left\{\begin{array}{cc}
1 & \left(\mathrm{NDVI}_{j}-\mathrm{NDVI}_{i}>0\right) \\
0 & \left(\mathrm{NDVI}_{j}-\mathrm{NDVI}_{i}=0\right) \\
-1 & \left(\mathrm{NDVI}_{j}-\mathrm{NDVI}_{i}<0\right)
\end{array}\right.
\end{gathered}
$$

式中, $\mathrm{NDVI}_{i}$ 和 $\mathrm{NDVI}_{j}$ 为第 $i j$ 年份的 NDVI 值, $n$ 为数据个数, $\operatorname{sgn}$ 为符号函数。当 $n \geqslant 10$ 时, 统计量 $S$ 近似服 从正态分布,所以定义标准化检验统计量 $Z$ :

$$
\begin{gathered}
Z=\left\{\begin{array}{cc}
\frac{S-1}{\sqrt{\operatorname{Var}(S)}} & (S>0) \\
0 & (S=0) \\
\frac{S+1}{\sqrt{\operatorname{Var}(S)}} & (S<0)
\end{array}\right. \\
\operatorname{Var}(S)=\frac{n(n-1)(2 n+5)}{18}
\end{gathered}
$$

当 $|Z|>1.65 、 1.96$ 和 2.58 时,表示趋势分别通过了置信度 $90 \% 、 95 \%$ 和 $99 \%$ 的显著性检验, 说明 NDVI 存 在显著变化趋势。

结合 $\beta$ 值和 $|Z|$ 值, 将 NDVI 变化趋势分为 4 个等级 ${ }^{[37]}: 0.01$ 置信水平下, 极显著增加 $(\beta \geqslant 0,|Z|>2.58)$ 、 极显著减少 $(\beta<0,|Z|>2.58) ; 0.05$ 置信水平下, 显著增加 $(\beta \geqslant 0,|Z|>1.96)$ 、显著减少 $(\beta<0,|Z|>1.96)$ 。

\subsection{3 相关分析}

本文利用 Pearson 相关分析来研究 NDVI 与极端气候的相关性,计算公式如下 ${ }^{[38]}$ :

$$
R=\frac{\sum_{i=1}^{n}\left(x_{i}-\bar{x}\right)\left(y_{i}-\bar{y}\right)}{\sqrt{\sum_{i=1}^{n}\left(x_{i}-\bar{x}\right)^{2} \sum_{i=1}^{n}\left(y_{i}-\bar{y}\right)^{2}}}
$$


式中, $R$ 为变量 $x 、 y$ 的相关系数, $x_{i}$ 为第 $i$ 年/月的 NDVI 值, $\bar{x}$ 为多年/年内各月 NDVI 平均值, $y_{i}$ 为第 $i$ 年/月 极端气温/降水指数值, $\bar{y}$ 为多年/年内各月极端气温/降水指数平均值。其中, 相关系数 $R$ 的取值范围为 $[-1,1], R$ 越大则表明变量之间的相关程度越强,并采用 $t$ 统计量进行显著性检验。滞后性分析是在多年月 尺度上研究 NDVI 与极端气候指数的相关性, 本文通过计算 NDVI 与前 $0-3$ 个月极端气候指数的相关系数, 研究植被对极端气候的滞后效应。

\section{3 结果与分析}

\subsection{NDVI 时空变化特征}

\subsection{1 时间变化趋势}

2001 - 2018 年间陕西省 NDVI 显著增长, 增长速率为 $0.06 / 10 \mathrm{a}(P<0.001)$, 说明陕西省植被覆盖整体呈 上升趋势。同时,陕西省各生态区 NDVI 变化趋势与年 NDVI 变化趋势相近,均呈显著上升趋势 (图 2)。其 中, II 区 NDVI 增长最快,增长速率达 $0.1 / 10 \mathrm{a}$, 说明该区域的植被恢复治理具有显著成效,而 III 区植被变化 速率最小,为 $0.031 / 10 \mathrm{a}$ 。

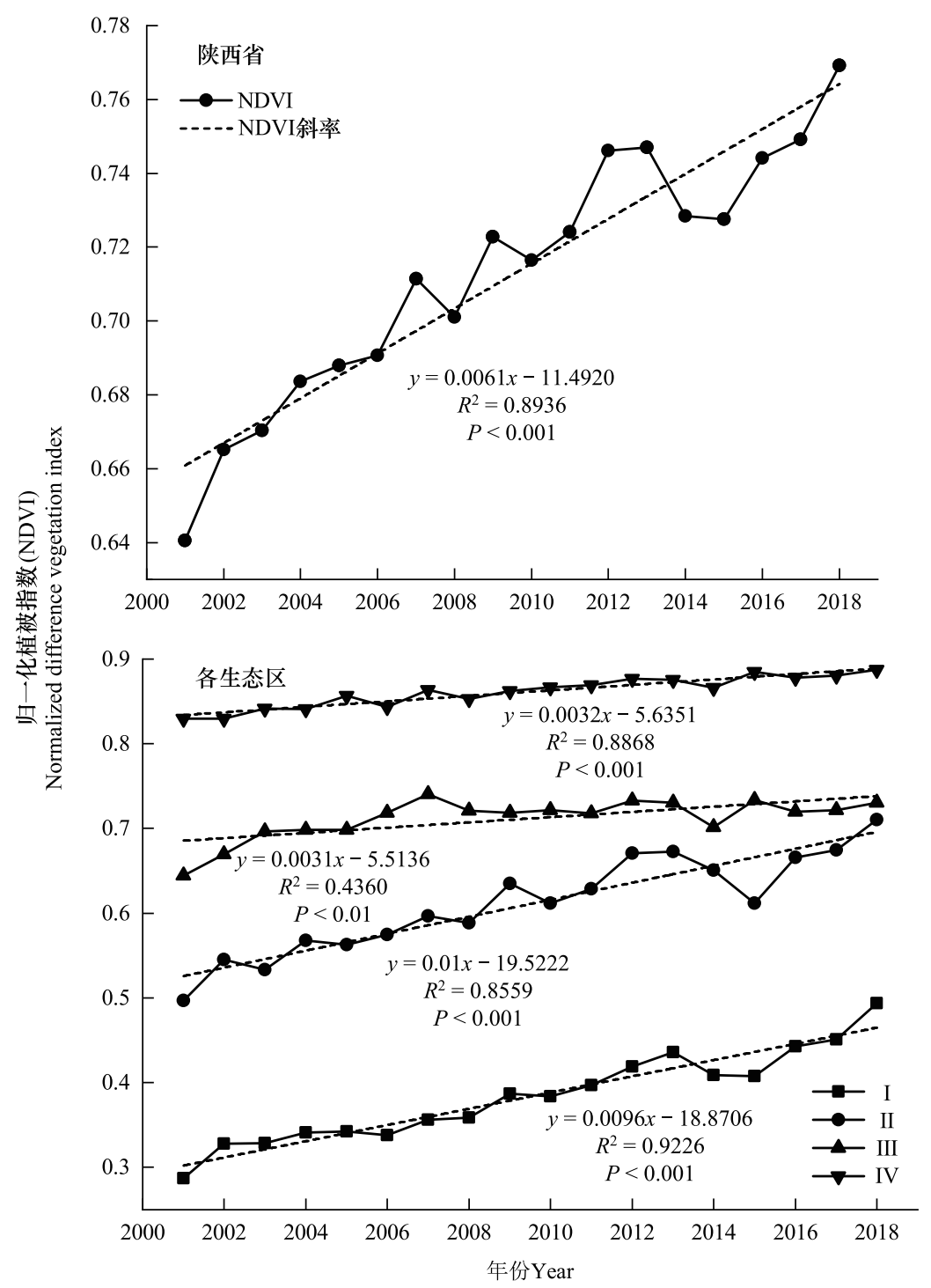

图 2 陕西省与各生态区 NDVI 年际变化趋势

Fig.2 Annual variation trend of NDVI in Shaanxi Province and different ecological areas 


\subsection{2 空间分布特征}

在空间分布上,陕西省年 NDVI 呈自南向北逐渐降低的空间格局 (图 3), 表现为 IV 区 (0.86)>III 区 $(0.71)>$ II 区 $(0.61)>$ 区 区 $(0.38)$ 。其中, II 区和 III 区的 NDVI 空间分布具有明显差异, II 区年 NDVI 高值主要 分布于区内南部黄土丘陵区, 北部黄土沟壑区的 NDVI 值相对较低; III 区植被覆盖整体较好, 年 NDVI 高值主 要分布于区内西部。

在空间变化趋势上,基于 Theil-Sen 斜率估计与 M-K 检验的方法,估算了 2001-2018 年植被覆盖的空间 变化趋势 (图 3)。结果表明, 研究区年 NDVI 整体呈增长趋势, 增长趋势面积占总面积 $93.07 \%$,远大于减少趋 势的面积 $(6.93 \%)$, 说明近 18 年陕西省内植被覆盖状况明显改善。其中,I 区和 II 区 NDVI 增加趋势显著,说 明区内植被生态恢复工程取得明显成效。值得注意的是, III 区中部地区 NDVI 呈极显著的减少趋势, 可能因 为该地区人口密集, 植被易受人类活动影响, 随着该区城镇化进程的加快, 部分农田和草地转为建筑用地, 一 定程度上加剧了植被退化, 致使植被覆盖有所降低 ${ }^{[28]}$ 。
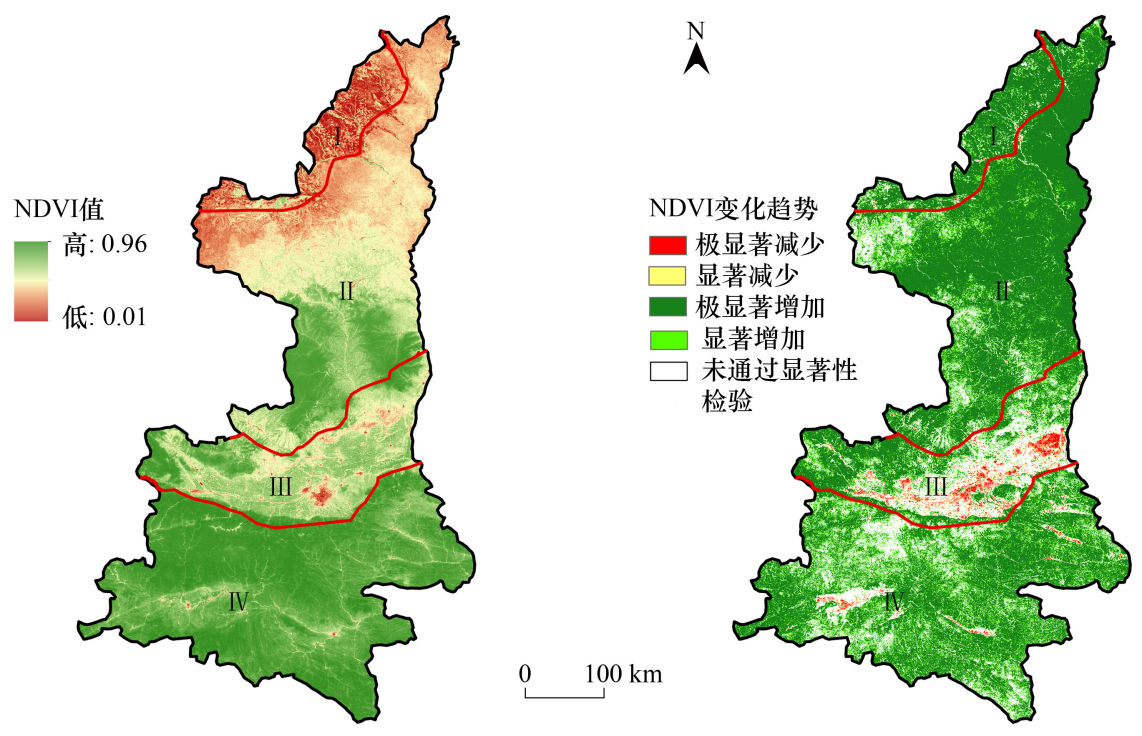

图 $32001-2018$ 年陕西省各生态区 NDVI 空间分布及变化趋势

Fig.3 Spatial distribution and variation trend of NDVI in different ecological areas in Shaanxi Province from 2001 to 2018

\subsection{NDVI 对极端气候的响应}

\subsection{1 年 NDVI 与极端气温的相关性}

图 4 表明整个研究区内, NDVI 与冷极值的平均相关系数绝对值在 0.2 以下, 普遍呈弱相关关系; NDVI 与 暖极值相关性较好, 其中与 TN90p 呈正相关的区域占 $85.30 \%$,且有 $11.17 \%$ 的区域呈显著正相关 $(P<0.05)$; NDVI 与 DTR 的相关系数在 $-0.896-0.860$ 之间,呈正相关与负相关区域分别占 $47.57 \%$ 和 $52.43 \%$, 这说明植 被覆盖与极端气温之间存在一定程度的联系。

同时,NDVI 与极端气温相关系数的分布规律具有明显的差异性。其中, NDVI 与冷极值 TMIN $_{\text {mean }}$ 在秦岭 以北相关性较弱; 在 IV 区内则多呈正相关, 其中呈正相关区域占 $78.66 \%$, 且有 $17.59 \%$ 呈显著正相关 $(P<$ $0.05)$, 说明日最低温升高, 在一定程度上降低了该区植被日间受低温伤害的风险, 更好地促进植被生长发育。 除 III 区中部地区以外, NDVI 与暖极值 TN90p 多呈正相关, 说明随着暖夜日数的增加, 夜间积温充足, 为植被 创造了适宜的生长条件。NDVI 与暖极值 $\mathrm{TN}_{\mathrm{x}}$ 呈负相关的区域主要分布于 I 区和 II 区北部, 平均相关系数分 别为 -0.25 和 -0.20 , 分别有 $16.81 \%$ 和 $18.58 \%$ 区域呈显著负相关 $(P<0.05)$, 而 NDVI 与 DTR 在 II 区中部多呈 正相关, 平均相关系数为 0.14 , 在其他 3 个生态区则多呈负相关。 

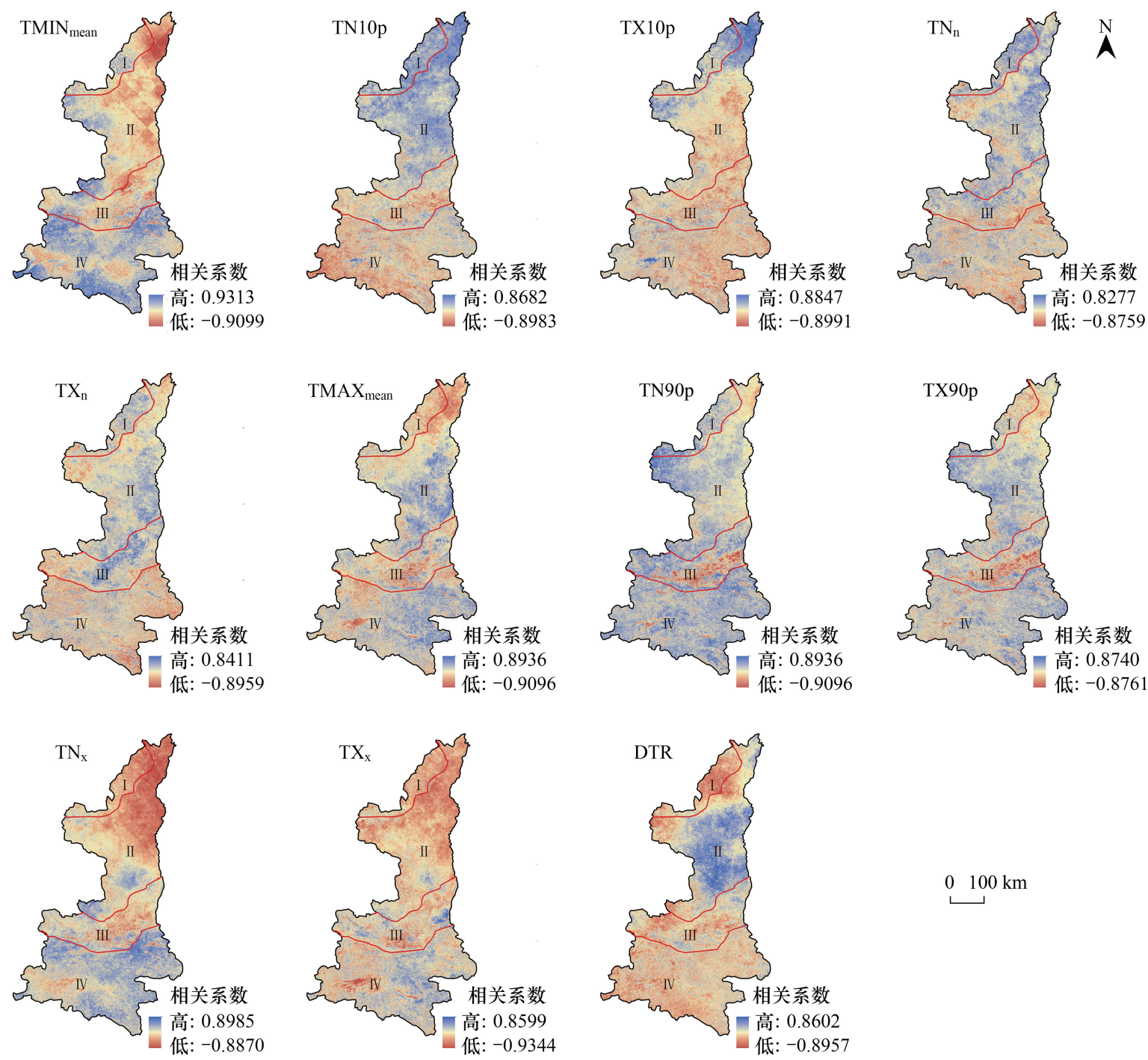

$0 \quad 100 \mathrm{~km}$

图 4 陕西省年 NDVI 与极端气温指数的相关性

Fig.4 Correlation between annual NDVI and extreme temperature indices in Shaanxi Province

$\mathrm{TMIN}_{\text {mean }}$ : 最低气温 Monthly average value of daily minimum temperature; TN10p : 冷夜日数 Percentage of days when TN $<10^{\text {th }}$ percentile; TX10p : 冷 昼日数 Percentage of days when $\mathrm{TX}<10^{\text {th }}$ percentile; $\mathrm{TN}_{n}$ : 日最低气温的极低值 Monthly minimum value of daily minimum temperature; $\mathrm{TX}_{\mathrm{n}}$ : 日最 高气温的极低值 Monthly minimum value of daily maximum temperature; $\operatorname{TMAX}_{\text {mean }}$ : 最高气温 Monthly average value of daily maximum temperature; TN90p: 暖夜日数 Percentage of days when $T N>90^{\text {th }}$ percentile; TX90p : 暖昼日数 Percentage of days when $T X>90^{\text {th }}$ percentile; $\mathrm{TN}_{\mathrm{x}}$ : 日最低气温的 极高值 Monthly maximum value of daily minimum temperature; $\mathrm{TX}_{\mathrm{x}}$ : 日最高气温的极高值 Monthly minimum value of daily maximum temperature; DTR:气温日较差 Daily temperature range

\subsection{2 年 NDVI 与极端降水的相关性}

图 5 结果表明, NDVI 与极端降水指数 PRCPTOT、Rx1day Rx5day 和 SDII 的平均相关系数分别为 0.20 、 $0.13 、 0.12$ 和 0.20 , 呈正相关的区域分别占整个区域的 $77.57 \% 、 66.80 \% 、 64.68 \%$ 和 $78.56 \%$, 其中分别有 $15.99 \% 、 12.54 \% 、 11.12 \%$ 和 $15.07 \%$ 的区域呈显著正相关 $(P<0.05)$ 。同时, NDVI 与极端降水的相关性具有明 显的空间异质性,主要表现为:呈显著正相关的区域多分布于 I 区和 II 区东北部,说明在半干旱地区降水能够 有效地促进植被生长。而 III 区和 IV 区 NDVI 与极端降水呈正相关关系, 平均相关系数在 $0-0.2$ 之间,但大 多未通过显著性检验,相关性总体较弱。 

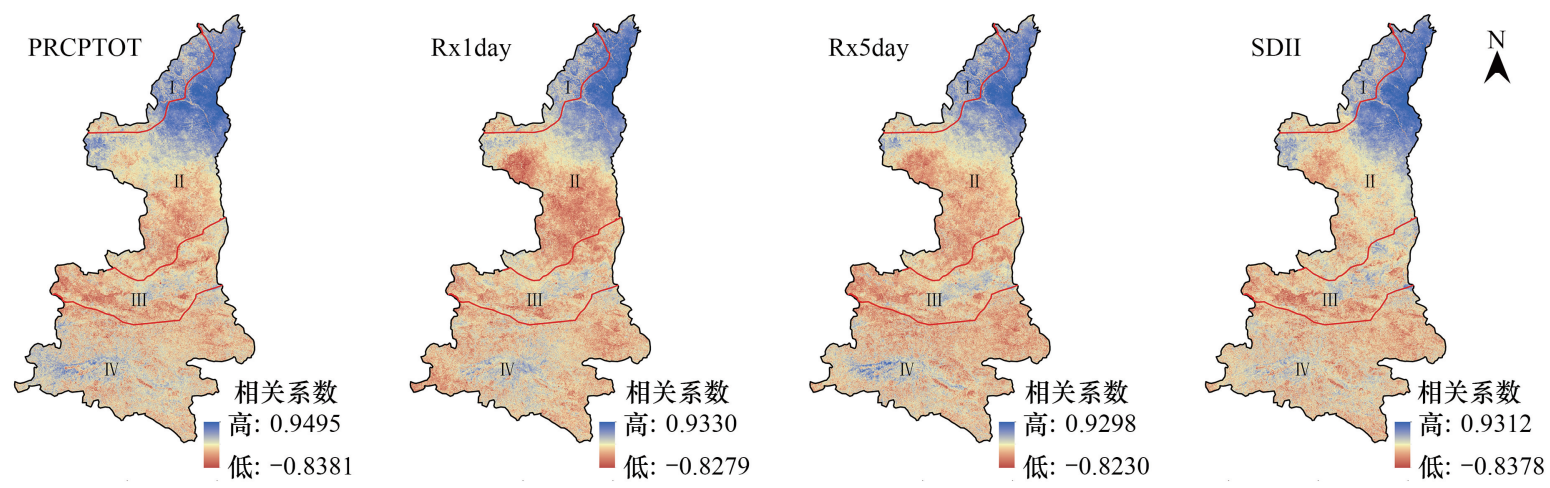

$0 \quad 100 \mathrm{~km}$

图 5 陕西省年 NDVI 与极端降水指数的相关性

Fig.5 Correlation between annual NDVI and extreme precipitation indices in Shaanxi Province

PRCPTOT: 年总降水量 Annual total precipitation in wet days;Rx1day: 单日最大降水量 Monthly maximum 1-day precipitation; Rx5day: 连续 5 日 最大降水量 Monthly maximum consecutive 5-day precipitation;SDII: 年均雨日降水强度 Simple precipitation intensity index

3.3 NDVI 对极端气候的滞后响应

\subsubsection{NDVI 与极端气温的滞后性分析}

从图 6 中可以看出, 各生态区极端气温指数与同期 NDVI 总体呈显著正相关, 仅有 TX10p 和 TX90p 未通 过显著性检验, 整体反应出气温对于陕西省植被恢复起正向促进作用。I 区和 II 区内极端气温指数 $\mathrm{TMIN}_{\text {mean }} 、 \mathrm{TN}_{\mathrm{n}} 、 \mathrm{TX}_{\mathrm{n}} 、 \mathrm{TMAX}_{\text {mean }} 、 \mathrm{TN}_{\mathrm{x}}$ 和 $\mathrm{TX}_{\mathrm{x}}$ 与同期、滞后 1 月、2 月和 3 月的 NDVI 均呈显著正相关, 表明区域 NDVI 对极端气温的滞后响应显著; DTR 与同期 NDVI 则呈显著负相关, 相关系数分别为 -0.438 和 -0.305 , 这 说明随着气温日较差的减小, 能够增强草地植被生态系统的碳固定能力 ${ }^{[39]}$, 从而促进植被生长; 而与滞后 2 月和 3 月 NDVI 呈显著正相关, 可以说明植被生长对极端气温的响应需要一定的时间周期, 滞后期可达 3 个月。

III 区和 IV 区内极端气温指数 $\mathrm{TMIN}_{\text {mean }} 、 \mathrm{TN}_{\mathrm{n}} 、 \mathrm{TX}_{\mathrm{n}} 、 \mathrm{TMAX}_{\text {mean }} 、 \mathrm{TN}_{\mathrm{x}}$ 和 $\mathrm{TX}_{\mathrm{x}}$ 与滞后 1 月和 2 月的 NDVI 呈显 著正相关,具有明显的滞后效应, DTR 与 NDVI 的滞后时间则达 3 个月。值得注意的是, III 区 NDVI 与同期 $\mathrm{TN} 10 \mathrm{p}$ 呈显著负相关, 说明夜间气温过低容易造成积温不足,影响植被生长。

3.3.2 NDVI 与极端降水的滞后性分析

由于极端降水指数 PRCPTOT 和 SDII 为年总降水量和年均雨日降水强度,所以选取 Rx1day 和 Rx5day 进 行多年月尺度上的滞后性分析。由图 7 可知, 各生态区极端降水指数 Rx1day 和 Rx5day 与同期 NDVI 呈显著 正相关, 反映降水总体有利于植被生长。同时, 极端降水指数与滞后 1 月和 2 月的 NDVI 均呈显著正相关, 表 明 NDVI 对降水具有一定的滞后性。值得注意的是, III 区和 IV 区极端降水与滞后 3 月的 NDVI 呈显著负相 关, 表明极端降水对植被生长起一定的抑制作用。

\section{4 讨论}

\subsection{NDVI 的动态变化}

2001-2018 年间, 陕西省内 NDVI 值总体呈显著上升趋势, 整体植被覆盖状况改善明显, 与岳辉等 ${ }^{[28]}$ 、钱 琛 ${ }^{[29]}$ 关于陕西省 NDVI 变化趋势研究结果一致。从空间分布特征来看,陕西省 NDVI 分布的空间异质性明显 (图 3), 呈现出南高北低的空间分布格局,这可能是由于南部水热条件较好, 植被类型主要是阔叶林, 而北部 植被类型主要是草原,体现出不同植被类型导致了 NDVI 值的空间差异 ${ }^{[40]}$, 而 II 区和 III 区 NDVI 空间分布差 异明显, 还可能是由于受土地利用类型、人类活动的影响 ${ }^{[3]}$ 。但从 NDVI 的空间变化趋势来看 (图 3), 北部 


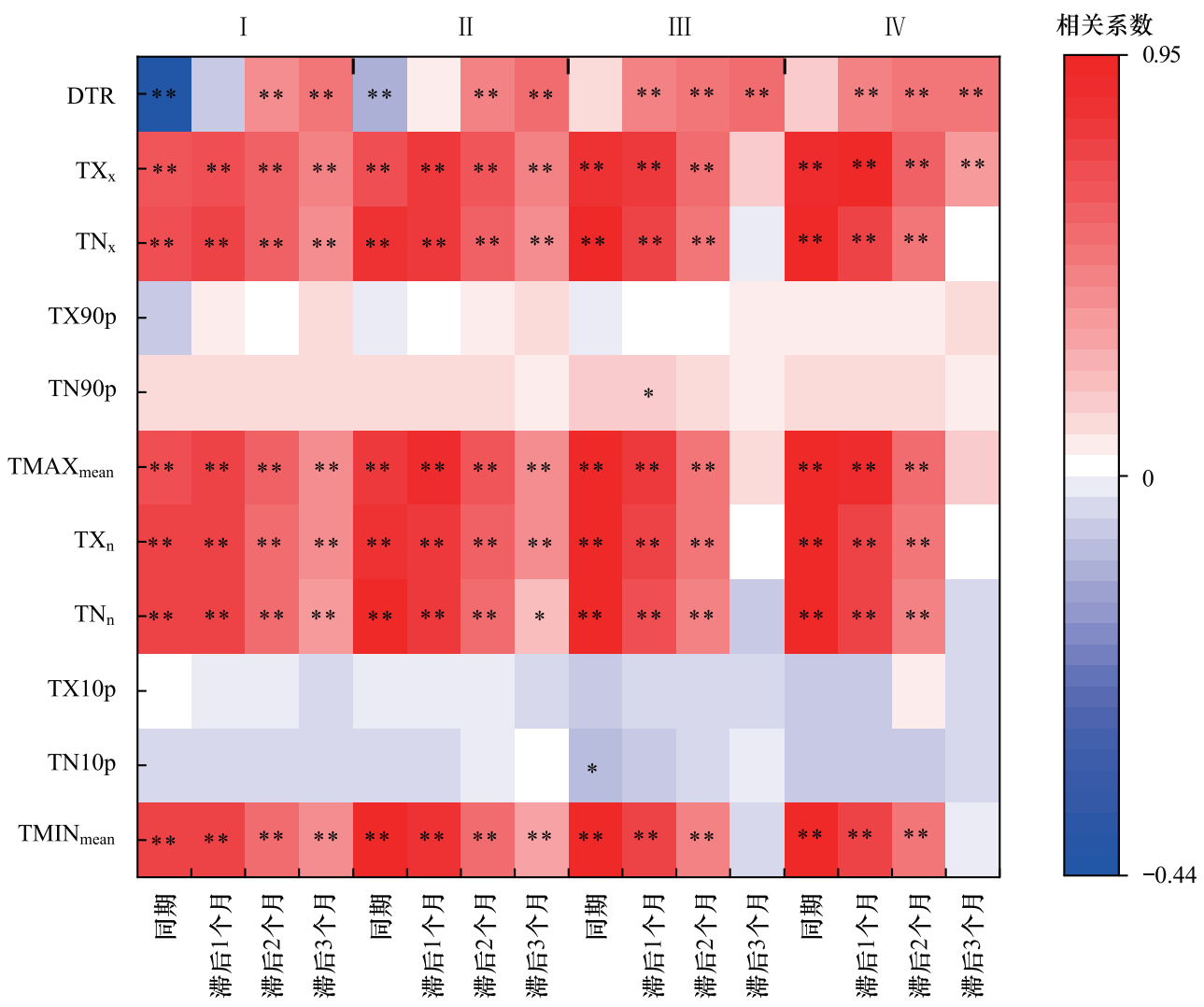

图 6 不同生态区极端气温指数与同期、滞后 1 个月、2 个月和 3 个月的 NDVI 相关性统计

Fig.6 Correlation coefficients between NDVI and extreme temperature indices for time lags in different ecological areas $* *$ 在 0.01 水平 (双侧) 上显著相关; *在 0.05 水平 (双侧) 上显著相关;滞后 2 个月 2 months later

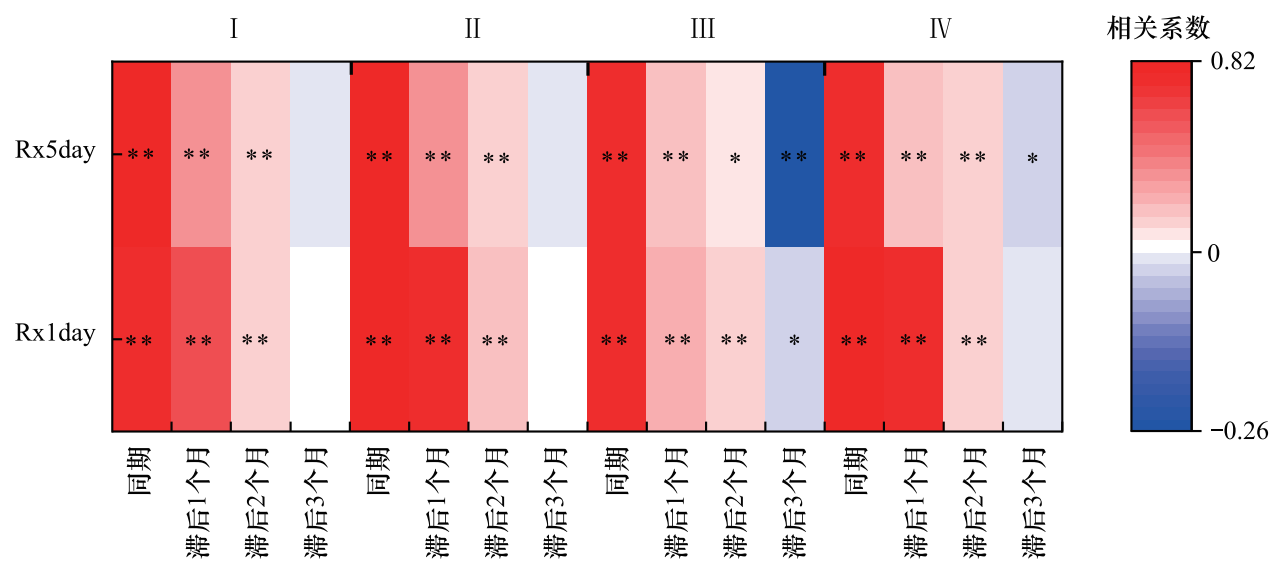

图 7 不同生态区极端降水指数与同期、滞后 1 个月、 2 个月和 3 个月 NDVI 的相关性统计

Fig.7 Correlation coefficients between NDVI and extreme precipitation indices for time lags in different ecological areas $* *$ 在 0.01 水平 (双侧) 上显著相关; $*$ 在 0.05 水平 (双侧) 上显著相关

NDVI 呈极显著增加趋势, 尤其是府谷、神木、佳县、子长以及安塞等地区, 因退耕还林还草、“三北”防护林工 程和防沙治沙等大规模的植被保护与恢复工程的实施,使得该区域植被覆盖得到了明显恢复。

\subsection{NDVI 对极端气温的响应}

从 NDVI 与极端气温指数的相关系数计算结果来看, 不同时间尺度上各生态区 NDVI 对极端气温响应程 
度不同。年际尺度上, I 区 NDVI 与 TN90p 呈正相关, 说明随着夜间气温升高, 夜间积温充足, 可以避免植被受 极端低温危害, 有利于植被生长; 与 $\mathrm{TN}_{\mathrm{x}}$ 呈负相关, 多是由于该区为温带草原区, 随着日间气温升高, 增加了植 被蒸腾和土壤水分蒸发, 抑制了该区灌草植被的生长 ${ }^{[41]}$ 。II 区中部 NDVI 与 DTR 多呈正相关, 这可能是因为 日高温或日低温的升高,增加了地表蒸发量, 从而加快了土壤水分的挥发, 当气温超过了适宜植被生长的最佳 温度时, 植被的净光合作用下降 ${ }^{[42]}$, 随着夜间气温的升高, 植物夜间呼吸作用增强, 不利于有机质的积累, 进 而减缓了植被生长。III 区内中部地区 NDVI 与暖极值多呈负相关, 这可能由于该区中部气温升高导致植被的 蒸散发增加, 从而加快了土壤水分的消耗, 影响植被的正常生长状态 ${ }^{[43]}$ 。IV 区 NDVI 与 TMIN mean 和 TN90p 呈 显著正相关, 这与黄土高原地区的研究结果一致 ${ }^{[21]}$ 。

多年月尺度上, 各生态区在考虑滞后三个月的情况下, NDVI 与极端气温指数 $\mathrm{TMIN}_{\text {mean }} 、 \mathrm{TN}_{\mathrm{n}} 、 \mathrm{TX}_{\mathrm{n}}$ 、 $\mathrm{TMAX}_{\text {mean }} 、 \mathrm{TN}_{\mathrm{x}} 、 \mathrm{TX}_{\mathrm{x}}$ 和 DTR 均呈显著正相关, 说明植被生长对极端气温的响应具有明显的滞后效应, 进而可以 反映出植被生长反馈于气温需要一定的时间, 可能是由于受到土壤温度变化和土壤有机质分解过程的 影响 ${ }^{[44]}$ 。

\subsection{NDVI 对极端降水的响应}

不同生态区内,NDVI 对极端降水的响应具有差异性。I 区和 II 区年 NDVI 与极端降水呈显著正相关,说 明降水能够促进植被生长, 这可能是由于两个生态区较为干旱, 水资源相对匮乏, 使得水分为植被生长的主要 限制条件 ${ }^{[11,14]}$ 。多年月尺度上, 极端降水对植被的影响滞后两个月, 这可能是由于在干旱和半干旱地区植物 生长受到水分胁迫,降水通过土壤渗透被植被根系吸收的过程需要一定的时间间隔 ${ }^{[18]}$, 致使植被对降水的响 应有所延迟。

III 区和 IV 区年 NDVI 与极端降水相关性并不显著, 与极端气温相比较, 这两个生态区植被生长对降水相 对不敏感, 可能是由于区域内气候湿润, 植被有足够的生长所需水分, 气温一定程度上成为植被生长的主要影 响因素 ${ }^{[7]}$ 。多年月尺度上, 在考虑滞后两个月的情况下, NDVI 与极端降水呈显著正相关, 反映出植被对累积 降水的滞后响应,这与降水丰沛地区的鄱阳湖流域结果较一致 ${ }^{[33]}$ 。

极端气温与极端降水均影响着研究区植被生长, 且存在一定的区域差异性, 同时 NDVI 对极端气候的响 应具有明显的滞后效应, 这与气候平均态对植被的影响规律一致 ${ }^{[24]}$ 。极端气候对植被覆盖的影响是一个复 杂的过程, 会受到其他非气候因素干扰。文章以极端气候指数分析了极端气候对 NDVI 的影响,但尚未考虑 具体的极端气候事件,今后研究中可着重分析 NDVI 对具体极端事件的响应关系。

\section{5 结论}

本文分析了陕西省 2001-2018 年 NDVI 的时空变化特征, 并结合日最高低气温和降水数据, 探讨了 NDVI 对极端气温和极端降水的响应特征, 得到以下结论:

(1) 陕西省及其各生态区的 NDVI 变化均呈显著上升趋势 $(P<0.001)$, 省内总体增长速率为 $0.06 / 10 \mathrm{a}$; 空 间上 NDVI 呈南高北低的分布特点, 其中陕北北部典型草原生态区 (I) NDVI 值最低为 0.38 , 秦巴山地落叶与 阔叶林生态区 $($ IV $)$ 的 NDVI 值最高为 0.86 。

(2) 年际尺度上, NDVI 对极端气候的响应具有明显的空间差异,陕北北部典型草原生态区 (I) 和黄土高 原农业与草原生态区 (II) 气候较干旱, NDVI 对极端降水响应敏感。汾渭盆地农业生态区 (III) 和秦巴山地落 叶与阔叶生态区 (IV) NDVI 与极端气温的相关性更为显著。

(3) 多年月尺度上, NDVI 对极端气候的响应具有一定的滞后效应。其中, 各生态区 NDVI 与极端气温 $\mathrm{TMIN}_{\text {mean }} 、 \mathrm{TN}_{\mathrm{n}} 、 \mathrm{TX}_{\mathrm{n}} 、 \mathrm{TMAX}_{\text {mean }} 、 \mathrm{TN}_{\mathrm{x}}$ 和 $\mathrm{TX}_{\mathrm{x}}$ 均呈显著正相关, 滞后期可达 3 个月。各生态区 NDVI 对 DTR 存在 滞后 2 月和 3 月的显著响应, 但陕北北部典型草原生态区(I) 和黄土高原农业与草原生态区 (II) NDVI 与同期 DTR 呈显著负相关。同时, 各生态区 NDVI 对极端降水 Rx1day 和 Rx5day 均呈显著正相关, 且滞后期可达 2 个月。 


\section{参考文献 (References) :}

[ 1 ] Zhu Y K, Zhang J T, Zhang Y Q, Qin S G, Shao Y Y, Gao Y. Responses of vegetation to climatic variations in the desert region of northern China. CATENA, 2019, 175: 27-36.

[ 2 ] Gao J B, Jiao K W, Wu S H. Investigating the spatially heterogeneous relationships between climate factors and NDVI in China during 1982 to 2013. Journal of Geographical Sciences, 2019, 29(10) : 1597-1609.

[ 3 ] 金凯, 王飞, 韩剑桥, 史尚渝, 丁文斌. 1982-2015 年中国气候变化和人类活动对植被 NDVI 变化的影响. 地理学报, 2020, 75(5)： 961-974.

[ 4 ] Melville T, Sutherland M, Wuddivira M N. Assessing trends and predicting the cover management factor in a tropical island state using Enhanced Vegetation Index. SN Applied Sciences, 2020, 2(10): 1686.

[ 5 ] 王云霓, 邓秀秀, 王彦辉, 曹恭祥, 于澎涛, 熊伟, 徐丽宏. 六盘山南坡华北落叶松人工林冠层 LAI 的坡面尺度效应. 生态学报, 2016, 36(12) : 3564-3571.

[ 6 ] Lamchin M, Park T, Lee J Y, Lee W K. Monitoring of vegetation dynamics in the Mongolia using MODIS NDVIs and their relationship to rainfall by Natural Zone. Journal of the Indian Society of Remote Sensing, 2015, 43(2) : 325-337.

[ 7 ] 陈超男, 朱连奇, 田莉, 李新鸽. 秦巴山区植被覆盖变化及气候因子驱动分析. 生态学报, 2019, 39(9): 3257-3266.

[ 8 ] 李双双, 延军平, 万佳. 近 10 年陕甘宁黄土高原区植被覆盖时空变化特征. 地理学报, 2012, 67(7) : 960-970.

[ 9 ] Mo K L, Chen Q W, Chen C, Zhang J Y, Wang L, Bao Z X. Spatiotemporal variation of correlation between vegetation cover and precipitation in an arid mountain-oasis river basin in northwest China. Journal of Hydrology, 2019, 574: 138-147.

[10] Zheng Y T, Han J C, Huang Y F, Fassnacht S R, Xie S, Lü E Z, Chen M. Vegetation response to climate conditions based on NDVI simulations using stepwise cluster analysis for the Three-River Headwaters region of China. Ecological Indicators, 2018, 92: 18-29.

[11] Craine J M, Ocheltree T W, Nippert J B, Towne E G, Skibbe A M, Kembel S W, Fargione J E. Global diversity of drought tolerance and grassland climate-change resilience. Nature Climate Change, 2013, 3(1) : 63-67.

[12] Ndayisaba F, Guo H, Isabwe A, Bao A M, Nahayo L, Khan G, Kayiranga A, Karamage F, Muhire E N. Inter-annual vegetation changes in response to climate variability in Rwanda. Journal of Environmental Protection, 2017, 8(4): 464-481.

[13] Pearson R G, Phillips S J, Loranty M M, Beck P S A, Damoulas T, Knight S J, Goetz S J. Shifts in Arctic vegetation and associated feedbacks under climate change. Nature Climate Change, 2013, 3(7): 673-677.

～14］张含玉, 方怒放, 史志华. 黄土高原植被覆盖时空变化及其对气候因子的响应. 生态学报, 2016, 36(13): 3960-3968.

［15］刘宪锋, 潘耀忠, 朱秀芳, 李双双. 2000-2014 年秦巴山区植被覆盖时空变化特征及其归因. 地理学报, 2015，70(5)：705-716.

[16］郑景云, 郝志新, 方修琦, 葛全胜. 中国过去 2000 年极端气候事件变化的若干特征. 地理科学进展, 2014, 33(1): 3-12.

[17] 何航, 张勃, 候启, 李帅, 马须, 马尚谦. 1982-2015 年中国北方生长季 NDVI 变化及其对气温极值的响应. 干旱区研究, 2020, 37(1)： 244-253.

[18］庞静，杜自强，张霄羽. 新疆地区植被对水热条件的时滞响应. 中国农业资源与区划, 2015, 36(7): 82-88.

[19] Arnone III J A, Verburg P S J, Johnson D W, Larsen J D, Jasoni R L, Lucchesi A J, Batts C M, Von Nagy C, Coulombe W G, Schorran D E, Buck P E, Braswell B H, Coleman J S, Sherry R A, Wallace L L, Luo Y Q, Schimel D S. Prolonged suppression of ecosystem carbon dioxide uptake after an anomalously warm year. Nature, 2008, 455(7211): 383-386.

[20］王晓利, 侯西勇. 1982-2014 年中国沿海地区归一化植被指数(NDVI) 变化及其对极端气候的响应. 地理研究, 2019, 38(4)：807-821.

[21］韩丹丹, 穆兴民, 高鹏, 赵广举, 孙文义, 田鹏. 黄土高原地区植被变化及其对极端气候的响应. 水土保持通报, 2020, 40(2): 247-254.

[22] Li C L, Wang J, Hu R C, Yin S, Bao Y H, Ayal D Y. Relationship between vegetation change and extreme climate indices on the Inner Mongolia Plateau, China, from 1982 to 2013. Ecological Indicators, 2018, 89: 101-109.

[23] Wu D H, Zhao X, Liang S L, Zhou T, Huang K C, Tang B J, Zhao W Q. Time-lag effects of global vegetation responses to climate change. Global Change Biology, 2015, 21(9): 3520-3531.

[24] 丁明军, 张镱锂, 刘林山, 王兆锋, 杨续超. 青藏高原植被覆盖对水热条件年内变化的响应及其空间特征. 地理科学进展, 2010, 29(4)： 507-512.

［25］赵舒怡, 宫兆宁, 刘旭颖. 2001-2013 年华北地区植被覆盖度与干旱条件的相关分析. 地理学报, 2015, 70(5): 717-729.

[26] 张清雨, 赵东升, 吴绍洪, 戴尔阜. 基于生态分区的内蒙古地区植被覆盖变化及其影响因素研究. 地理科学, 2013, 33( 5) : 594-601.

[27］秦超, 李君轶, 陈宏飞, 包珺玮, 宋光飞. 陕西省植被覆盖时空演变特征及其与气候因子的关系. 中国农业气象, 2015, 36(1): 108-114.

[28］岳辉, 刘英. 近 15a 陕西省植被时空变化与影响因素分析. 干旱区地理, 2019, 42(2): 314-323.

[29］钱琛, 陈海滨, 侯现慧. 生态建设背景下陕西省植被覆盖时空变化及其影响因素研究. 干旱区地理, 2020, 43(2): 425-433. 
[30］何艳芬, 张喨. 陕西省 1980-2006 年气候变化时空特征研究. 干早区资源与环境, 2011, 25(11): 59-63.

[31] Holben B N. Characteristics of maximum-value composite images from temporal AVHRR data. International Journal of Remote Sensing, 1986, 7 (11) : 1417-1434.

[32] Frich P, Alexander L V, Della-Marta P, Gleason B, Haylock M, Tank A M G K, Peterson T. Observed coherent changes in climatic extremes during the second half of the twentieth century. Climate Research, 2002, 19(3): 193-212.

[33] Tan Z Q, Tao H, Jiang J H, Zhang Q. Influences of climate extremes on NDVI ( Normalized Difference Vegetation Index) in the Poyang lake basin, China. Wetlands, 2015, 35(6): 1033-1042.

[34] Sen P K. Estimates of the regression coefficient based on Kendall's Tau. Journal of the American Statistical Association, 1968, 63 ( 324 ) : 1379-1389.

[35] Mann H B. Nonparametric tests against trend. Econometrica, 1945, 13(3) : 245-259.

[36] Kendall M G. Rank Correlation Methods. London: Griffin, 1970.

[37] 孙锐, 陈少辉, 苏红波. 黄土高原不同生态类型 NDVI 时空变化及其对气候变化响应. 地理研究, 2020, 39(5)：1200-1214.

[38］神祥金, 张佳琦, 吕宪国. 青藏高原沼泽湿地植被 NDVI 时空变化及其对气候变化的响应. 生态学报, 2020, 40(18)：6259-6268.

[39] 李峰, 李琪, 薛红喜, 吴东丽, 王云龙. 温度对克氏针茅草原生态系统生长季碳通量的影响. 农业环境科学学报, 2012, 31 ( 7) : 1453-1459.

[40］刘静，温仲明，刚成诚. 黄土高原不同植被覆被类型 NDVI 对气候变化的响应. 生态学报, 2020,40(2)：678-691.

[41] 许旭, 李晓兵, 梁涵玮, 黄玲梅. 内蒙古温带草原区植被盖度变化及其与气象因子的关系. 生态学报, 2010, 30 (14) : 3733-3743.

[42] 王海军, 靳晓华, 李海龙, 张勃, 戴声佩. 基于 GIS 和 RS 的中国西北 NDVI 变化特征及其与气候变化的耦合性. 农业工程学报, 2010,26 (11) : 194-203.

[43] 葛非凡, 毛克彪, 蒋跃林, 谭雪兰, 赵映慧, 夏浪. 华东地区夏季极端高温特征及其对植被的影响. 中国农业气象, 2017, 38( 1): 42-51.

[44] Cui L L, Shi J. Temporal and spatial response of vegetation NDVI to temperature and precipitation in eastern China. Journal of Geographical Sciences, 2010, 20(2): 163-176. 